\title{
MARXISMO E CIÊNCIA SOCIAL Um balanço crítico do marxismo analítico
}

\section{Renato Perissinotto}

Trinta anos após a publicação de Karl Marx's theory of history: a defense, de G. A. Cohen, e passados alguns anos do debate que ele suscitou, acreditamos ser importante discutir algumas das proposiçōes apresentadas pela corrente teórica que, na esteira desse debate, ficou conhecida como "marxismo analítico". O marxismo analítico deu origem a um vigoroso programa de pesquisa que produziu um sem-número de investigações sobre temas importantes no âmbito da teoria marxista, como ação coletiva, organização e formação de classe, conceituação das classes médias, teoria econômica e da exploração e o problema normativo da emancipação humana. ${ }^{1}$

Este texto, entretanto, propõe-se a discutir tão-somente as proposiçôes teórico-metodológicas do marxismo analítico, sem entrar na análise de qualquer um dos temas substantivos listados acima.

Artigo recebido em fevereiro/2009

Aprovado em dezembro/2009
Esta abordagem justifica-se porque é exatamente nos aspectos teóricos e metodológicos que reside a proposta de renovação do marxismo apresentada pelos analíticos. Desse ponto de vista, aliás, justifica-se também a freqüência com que nos referimos ao nome de Jon Elster. Este autor foi, sem dúvida alguma, o mais radical e ardoroso defensor dessa proposta metodológica. Foi ele quem mais insistiu, de forma às vezes evidentemente exagerada, na necessidade de reformulação do marxismo em direção a uma "teoria analítica" que conferisse àquele corpo teórico maior robustez científica. Os outros autores, favoráveis ou contrários a essa proposta, de uma maneira ou de outra estão sempre dialogando com Elster. ${ }^{2}$

No entanto, mais do que o seu ardor na defesa da reconstrução do marxismo, o que justifica conferir especial atenção às consideraçôes de Jon Elster é o fato de ele discutir temas mais significativos para a teoria sociológica. G. A. Cohen, por 
exemplo, preocupava-se essencialmente com a "reconstrução" do marxismo a partir de uma releitura dos textos clássicos sob as lentes da filosofia analítica, com o objetivo de conferir precisão lógica e lingüística aos conceitos marxianos; John Romer, por sua vez, dedica-se fundamentalmente a redefinir as proposições da teoria econômica marxista de acordo com os cânones metodológicos da teoria econômica neoclássica (Tarrit, 2006, p. 600). As proposiçōes de Elster, a nosso ver, tocam em pontos que interessam mais diretamente à teoria sociológica, como a sua crítica à explicação funcional, ao individualismo metodológico e ao problema da ação coletiva.

$\mathrm{O}$ artigo está dividido em cinco partes: na primeira, apresentamos o traço mais marcante do marxismo analítico, qual seja, o seu objetivo de discutir o marxismo tradicional preferencialmente do ponto de vista do método; a segunda parte apresenta suas críticas à explicação de tipo funcional; em seguida, discutimos uma possível defesa desse mesmo tipo de explicação a fim de avaliar em que condiçóes ela poderia permanecer como elemento constitutivo do marxismo; na quarta parte, analisamos o instrumental teórico-metodológico dos analíticos que, segundo seus defensores, poderia prestar grandes serviços ao avanço científico do marxismo, a saber, o individualismo metodológico, a teoria da escolha racional e a teoria dos jogos; por fim, à guisa de conclusão, identificaremos o que, a nosso ver, vale a pena levar em consideração nas críticas feitas pelos marxistas analíticos a fim de fazer avançar o marxismo como ciência social.

\section{O problema do método}

Num famoso texto de 1919, Georg Lukács afirmava que a condição fundamental para que alguém se reconhecesse como marxista ortodoxo não residia na adesão incondicional às teses substantivas defendidas por Marx. Um marxista, baseado nos avanços da ciência econômica e da historiografia, poderia facilmente acatar a evidência dos fatos e recusar os erros de interpretação cometidos pelos clássicos e, ainda assim, continuar sendo um marxista. Isso seria possível porque um marxista ortodoxo se definiria pela sua adesão a um método específico (a dialética da totalidade) e não pela defesa intransigente desta ou daquela proposição sobre eventos particulares (Lukács, [1919] 1974, p. 24).

Essa posição, como se sabe, não é específica deste autor nem de sua época. Se há uma característica fortemente associada ao marxismo e aos marxistas é sua defesa permanente da especificidade e das vantagens do seu método ante os vícios individualistas e empiricistas da "ciência social burguesa". Desse modo, ainda em 1991, o marxista francês Alain Lipietz afirmava que, apesar de as conclusões de Marx terem sido refutadas pela história, era possível continuar sendo marxista quanto ao método e buscar explicaçōes mais pertinentes para o funcionamento do capitalismo contemporâneo e sua crise (1991, p. 102).

O projeto do marxismo analítico consiste, essencialmente, na rejeição desse pressuposto do marxismo tradicional. Para os autores filiados àquela corrente teórica, é preciso, primeiro, rejeitar as pretensões dos marxistas à especificidade metodológica e, segundo, fazer a crítica dos seus procedimentos supostamente científicos. $\mathrm{Na}$ verdade, segundo os marxistas analíticos, em especial Jon Elster, o grande problema metodológico do marxismo - tão grande a ponto de impedi-lo de fazer ciência - é exatamente o seu método, baseado, em termos gerais, em declaraçôes de tipo funcional sem capacidade explicativa.

Por isso, para que possamos entender melhor por que o uso do individualismo metodológico e da teoria da escolha racional poderia salvar o marxismo dos seus pecados metodológicos é preciso compreender primeiro a natureza da crítica feita pelos marxistas analíticos à explicação de tipo funcional.

\section{A explicação funcional não é uma explicação}

Elster identifica cinco passos característicos de uma explicação funcionalista, que podem ser assim resumidos: (i) inicialmente, constata-se que $Y$ é um efeito de $X$; (ii) em seguida, observa-se que $Y$ produz efeitos benéficos para o grupo $Z$; (iii) percebese, ainda, que o efeito $Y$ não foi intencionalmente perseguido pelos atores sociais que produziram $X$; 
(iv) além disso, constata-se que a relação causal entre o evento $X$ e o efeito $Y$ não é percebida pelos membros do grupo $Z$; e, por fim, $(v)$ a explicação funcional afirma que o fato de o efeito $Y$ ser benéfico para o grupo $Z$ é a explicação da existência e da persistência do evento $X$ por meio de um "círculo de retroalimentação causal” (Elster, 1989c, p. 55). Supõe-se, assim, a existência de algum mecanismo que garante a ocorrência/persistência do evento $X$ porque ele produz um efeito $(Y)$ benéfico para $Z$. Mais especificamente, no caso do marxismo, pretende-se explicar determinados fenômenos sociais sempre a partir das conseqüências benéficas que eles produzem para a classe dominante, ou por outra, sempre a partir da funcionalidade desses fenômenos para a reprodução da dominação de classe. Exemplos disso poderiam ser encontrados nas considerações de Marx sobre o Estado capitalista, a mobilidade social no capitalismo e as divisões étnicas no interior da classe operária (Elster, 1982, p. 457-459; 1989a, p. 244-250).

Jon Elster formula três críticas fundamentais à explicação funcional.

A primeira refere-se à sua fraqueza lógica. Segundo ele próprio, "a questão está em como explicar um fenômeno a partir de outro que acontece depois. Deve haver uma explicação para um fenômeno no momento de sua ocorrência; não pode ser necessário esperar pelas conseqüências para só então poder explicá-lo" (Elster, 1989b, p. 46). Ou seja, o equívoco consiste em pretender explicar o que vem antes pelo que vem depois, a causa pelo efeito.

A segunda crítica refere-se ao fato de esse tipo de "explicação" não revelar o mecanismo gerador do fenômeno. Quando, por exemplo, se diz que uma determinada política estatal existe por causa de seus benefícios para a classe capitalista, não se está dizendo absolutamente nada sobre como essa política foi gestada. Para Elster, a revelação desse mecanismo (o como) é fundamental para a ciência social, pois reside aí a sua capacidade explicativa (1991, p. 98).

Por fim, a terceira crítica, a mais importante de todas segundo o próprio Elster, refere-se ao fato de que "em muitas explicações funcionais, e não só no marxismo, o ciclo de realimentação não é demonstrado, mas apenas postulado ou tacitamente suposto (Elster, 1989b, p. 47).
Como vimos, faz parte da explicação funcional saltar da constatação da existência de uma funcionalidade entre $X$ e $Z$, por meio da produção do efeito $Y$, diretamente para a explicação da persistência de $X$. Pressupooe-se a existência de algum mecanismo social que garanta a persistência de $X$ apenas por ser ele funcional para $Z$, mas tal mecanismo nunca é efetivamente demonstrado. Nesse sentido, o fato de o analista realizar os quatro passos acima descritos não o autoriza, por si só, a dar o quinto passo. A existência de um mecanismo de alimentação que garanta a continuidade de $X$ devido à sua funcionalidade para $Z$ precisa ser demonstrada, caso contrário teremos apenas uma conclusão falaciosa (Elster, 1989c, p. 56). Para os marxistas analíticos em geral (exceto Cohen, como veremos), a explicação funcional é incapaz de atingir tal objetivo, pois se limita a identificar as funçôes de um determinado fenômeno, não fornecendo meios para explicar a sua gênese nem a sua persistência.

A gênese de um fenômeno não pode ser explicada funcionalmente porque, como vimos, seria logicamente equivocado fazê-lo. As causas devem ser cronologicamente anteriores ao fenômeno que se pretende explicar. Portanto, explicar a ocorrência de um fenômeno pelas suas conseqüências seria contrariar essa regra fundamental da explicação causal. Além disso, a relação entre uma instituição e suas conseqüências, por exemplo, entre uma política estatal e os benefícios que essa mesma política acarreta para uma classe, pode ser puramente acidental. Absolutamente nada garante que o fato de trazer conseqüências benéficas para um determinado grupo tenha alguma capacidade explicativa. $^{3}$

A persistência de um fenômeno, por sua vez, não pode ser explicada funcionalmente a menos que se revele um mecanismo social que desvende as relaçôes causais por meio das quais a funcionalidade garante a durabilidade do fenômeno em questão. Nesse sentido, a constatação de uma relação de funcionalidade entre $X$ e $Z$ (questão sociológica, diga-se, absolutamente legítima) não se constitui, por si só, na formulação de uma explicação causal da permanência de $X$.

É interessante observar que esse traço essencial da explicação funcional, que consiste em ex- 
plicar a gênese/persistência de um fenômeno a partir de suas funções objetivas, está estreitamente ligado a uma constatação bastante recorrente na teoria social como um todo, e não apenas no marxismo, a saber, que as ações humanas, ainda que guiadas por objetivos conscientes, produzem resultados que não correspondem às intenções dos atores. Como lembra Merton, várias podem ser as fontes causadoras dessa defasagem entre intenção e efeitos não-antecipados da ação: ignorância acerca do contexto, erro de avaliação, peso excessivo dos interesses imediatos na determinação da conduta, adesão radical a valores morais ou as chamadas "profecias suicidas" (Merton, 1979, pp. 202-208).

No entanto, em diversas ocasióes essa constatação resultou num outro tipo de explicação, da qual, aliás, o próprio Merton é um dos mais eminentes representantes. Defendeu-se que esses efeitos não antecipados da conduta deveriam ser explicados em função de determinadas necessidades sistêmicas (Merton, 1967, p. 106), que se imporiam aos agentes à revelia de suas consciências. Como se sabe, esta é a essência do conceito mertoniano de "funçōes latentes" (Idem, p. 105).

No marxismo, a defasagem entre motivos intencionais da ação e seus resultados objetivos foi quase sempre resolvida da mesma maneira. Nesse caso, como fica clara em importante passagem de Ludwig Feurbach e o fim da filosofia clássica alemã (Engels [1888] s/d, p. 198), a evidência de que os resultados das ações humanas não correspondem às intençôes dos seus autores só poderia ser explicada em função de leis imanentes que regem o curso da história. Esse espírito analítico está presente em todo o marxismo, ainda que assuma formas bem diferentes, aqui e ali. Assim, por exemplo, a consciência de classe, em Lukács (que se valeu dessa mesma passagem), não se confunde com a consciência psicológica dos operários empíricos, mas é um atributo objetivo da posição da classe operária dentro da totalidade social capitalista (Lukács, [1919] 1974, p. 64); o Estado capitalista, na teoria neomarxista, cumpre uma função objetiva sistêmica à revelia da consciência e das motivaçôes dos atores que estão à frente dessa instituição (Poulantzas, 1986); os fenômenos econômicos são, na verdade, efeitos de estruturas que contêm em si mesmas o seu próprio mecanismo causal, como sugere o conceito de "causalidade estrutural" de Louis Althusser (1970, pp. 197-207).

O problema, contudo, não é que essas teses sejam indefensáveis, mas sim que a sua operacionalização nunca revela os mecanismos por meio dos quais tais necessidades sistêmicas ou tais lógicas objetivas se traduzem em condutas humanas que, por sua vez, produzem os efeitos objetivos necessários à reprodução ou à mudança social. Nesse sentido, o individualismo metodológico tem lá suas vantagens, pois os teóricos filiados a essa vertente nunca precisaram recorrer a quaisquer "necessidades objetivas" do capitalismo ou a leis imanentes da história para explicar a defasagem entre açōes intencionais e resultados não-antecipados. Assim, a famosa distinção weberiana entre "compreensão" (dos motivos da ação) e "explicação" (do desenvolvimento externo da ação) ou o conceito de "efeitos perversos", formulado por Raymond Boudon, ${ }^{4}$ procuram dar conta dessa defasagem recorrendo às múltiplas condutas individuais que, agregadas, se constituem no mecanismo causador de efeitos coletivos que não são desejados por nenhum dos atores envolvidos na sua produção. Nesse sentido, se um efeito determinado é produzido, ele é causalmente conectado às condutas e às interaçôes humanas concretas e observáveis, isto é, a "um $s u$ jeito sociológico dotado de capacidade de ação e de intenção" (Boudon, 1993, p. 15), e não a uma "imposição objetiva" que opera nunca se sabe exatamente como.

Essas críticas à explicação funcional não devem, apesar disso, levar-nos às mesmas conclusōes exageradas de Jon Elster. Para Elster, a incoerência lógica e a incapacidade explicativa (isto é, incapacidade de revelar mecanismos) deste procedimento comprovariam que o mesmo não tem lugar na teoria social (Elster, 1982, p. 463). Se a explicação funcional não é efetivamente capaz de explicar e, por isso, deve ser excluída das ciências sociais, e se o procedimento básico do marxismo reside exatamente nesse tipo de explicação, a conclusão é que ou o marxismo abandona esse padrão explicativo ou perde sua capacidade científica. Mas isso seria claramente um exagero. 


\section{Uma defesa da explicação funcional}

Todas as críticas feitas às consideraçôes de Elster sobre a explicação funcional remetem-se à postura exageradamente negativa acima evidenciada. Mesmo aqueles que concordam com a idéia de que tal explicação não tem o poder de revelar mecanismos, discordam do exagero que consiste em expulsá-la do campo da ciência social. Nessa direção, podemos encontrar três tipos de argumentos favoráveis à explicação funcional: (i) ela é importante para a identificação de regularidades funcionais; (ii) trata-se de um procedimento complementar, e não oposto, à explicação intencional; e (iii) a explicação funcional é um trabalho preliminar que permite identificar os fenômenos sociais relevantes que merecem ser explicados.

\section{(i) Explicação funcional e regularidades}

Segundo Cohen, a explicação funcional é típica do marxismo e cumpre aí uma função importante: identificar regularidades. Este autor tem plena consciência de que é preciso diferenciar "enunciados funcionais" de "explicações funcionais”, já que a atribuição de funções a um dado fenômeno, reconhece ele, não configura por si só uma explicação desse mesmo fenômeno (2001, pp. 251-258). Nesse sentido, cabe perguntar: "se nem todo enunciado funcional é explicativo, o que torna um enunciado funcional explicativo?" (Idem, p. 256). Para ele, isso só ocorre quando se pode constatar que a relação entre a existência/persistência de um dado fenômeno e as conseqüências que ele produz assume a forma de uma "lei" (consequence law), isto é, uma regularidade passível de generalização (Idem, p. 259). Assim, se for possível demonstrar, por meio de evidência empírica fundamentada, que sempre que $A$ foi funcional para $B, A$ ocorreu, revelar-se-ia uma regularidade importante que poderia explicar a persistência de $A$, embora não necessariamente a sua gênese, isto é, o mecanismo pelo qual $A$ se formou ou pelo qual $B$ deu origem a $A$. Segundo Cohen, esse é o caminho mais simples para confirmar uma explicação funcional sem estabelecer um mecanismo (Cohen, 1982, pp. 490 e 495, n. 14). É importante insistir na idéia de "re- gularidade", pois é ela que garante que a ocorrência de A em função de sua funcionalidade para B não é meramente acidental.

Cohen observa que esse tipo de explicação não comete a infração lógica de explicar a causa pelas suas conseqüências. Para esclarecer esse ponto, ele formula o seu conceito de "fato disposicional" (dispositional fact). Esse conceito descreve as condições objetivas de uma sociedade que, em um dado momento, demanda determinadas consequiências para continuar existindo e, por isso, aumenta a probabilidade de ocorrência dos fenômenos intrinsecamente capazes de produzir tais conseqüências. Nesse sentido, é essa condição da sociedade que explica a ocorrência do fenômeno que se pretende explicar (explanandum), fenômeno esse que ocorre porque seus atributos (suas "disposições") são funcionais naquelas circunstâncias (Cohen, 2001, pp. 262 e 281).

O exemplo mais convincente dado por Cohen quanto a esse ponto diz respeito às estratégias adaptativas das indústrias diante do mercado capitalista, que ele chama de "elaboração darwiniana da explicação funcional”. Imaginemos uma economia competitiva em que certa indústria adotaria a estratégia gerencial de ampliar sua escala de produção, reduzindo significativamente seus custos e, por conseguinte, aumentando a sua eficiência econômica. Imaginemos ainda que os gerentes não tenham consciência desse fato. Nesse caso, a estratégia de ampliação da escala de produção prevaleceria porque as indústrias que não a adotassem sucumbiriam em face da competição com as demais empresas. Portanto, não é a intenção dos gerentes que explica a adoção dessa estratégia, nem suas conseqüências, mas os atributos objetivos do mercado capitalista que, por meio da competição, "seleciona" as estratégias gerenciais cujas "disposições" são mais adequadas ao funcionamento da economia naquele contexto, isto é, aquelas cujas conseqüências são funcionais para as empresas naquelas circunstâncias (Idem, pp. 287-289).

É preciso observar, entretanto, que esse exemplo é particularmente favorável à tese de Cohen, já que o mercado capitalista produz sinais inequívocos e bastante rápidos acerca da ineficiência de determinadas estratégias, a saber, a morte da empresa ineficiente. A aplicação da explicação funcional a partir da idéia 
de "fatos disposicionais" parece um pouco mais obscura em casos menos precisos e bem mais ambíguos, como o surgimento e a persistência de uma ideologia ou de uma religião (exemplos também utilizados por Cohen) dada a sua funcionalidade para a dominação de classe (Idem, pp. 290-296). Além disso, por mais que Cohen observe que "revelar mecanismos" não é o objetivo da explicação funcional, é bastante frustrante nada saber sobre o modo pelo qual uma "sociedade", em função de suas condiçōes objetivas, "seleciona" determinadas instituições e condutas devido à sua potencial funcionalidade para ela. ${ }^{5}$ Outro problema, como antecipa o próprio Cohen, é saber por que uma dada conduta ou instituição foi "escolhida" quando outras condutas e instituições poderiam executar a mesma função (Idem, pp. 274-277; Domenèch, 2009, p. 6).

De qualquer forma, de acordo com Cohen, o problema do marxismo reside menos nas dificuldades inerentes à explicação funcional e mais no uso pouco rigoroso que os marxistas fazem dela. Para ele, os marxistas, na maioria das vezes, falham até mesmo ao tentar satisfazer a exigência preliminar de mostrar que $A$ é, de fato, funcional para $B$. Ao dar o exemplo de análises sobre a funcionalidade de políticas estatais no capitalismo, Cohen afirma que, normalmente, a funcionalidade de determinada política estatal é tida quase como um pressuposto e que, uma vez estabelecida essa funcionalidade, o estudioso, sem mais argumentos, trata essa política também como funcionalmente explicada. Assim, diz ele, transita-se de " $A$ é funcional para $B$ " para " $B$ funcionalmente explica $A$ " sem experimentar nenhuma necessidade de justificar esse passo, sem perceber que se transitou de uma afirmação para outra, distinta e mais forte. A explicação funcional exige comprovação empírica exaustiva tanto da funcionalidade como da regularidade das conexôes funcionais, o que permitiria defender a tese acerca da persistência de um dado fenômeno devido à sua funcionalidade para um grupo social, classe ou instituição (1982, p. 491-492).

\section{(ii) Explicação funcional e explicação intencional}

Berger e Offe, com bastante bom senso, criticam em Elster aquilo que consideram uma busca infrutífera pela "pureza metodológica". Para ambos, deve-se utilizar uma abordagem funcionalista quando essa se mostra necessária, uma abordagem estruturalista quando as determinações estruturais forem evidentes o suficiente, uma análise baseada no "ator" quando a ação individual e a escolha se mostrarem fortemente presentes (1982, p. 523). ${ }^{6}$

Wright, Levine e Sober (1993, p. 119-123) utilizam o exemplo do racismo para defender uma "explicação funcional com um mecanismo intencional". Suponha-se uma sociedade capitalista marcada pela discriminação racial. Esse fenômeno produz um efeito funcional para a dominação de classe ao criar divisões étnicas no seio da classe operária que, por essa razão, não consegue resistir de maneira coesa à classe dominante. Os membros e representantes dessa última classe, ao perceberem a funcionalidade do racismo para a reproduçáo de sua posição dominante na estrutura social, passariam a incentivar o racismo intencionalmente. Nesse caso, como se percebe, há dois momentos da explicação: primeiro, quando se constata a funcionalidade da discriminação com base na "raça"; segundo, o momento da explicação propriamente dito, quando as intenções dos agentes explicam a reiteração do racismo.

Ora, na verdade essa proposta consiste, basicamente, na rejeição da explicação funcional, cuja característica fundamental, como lembra Merton, é a inconsciência dos atores acerca das funçōes latentes de suas condutas. No exemplo acima, a abordagem intencional é totalmente predominante e a "funcionalidade" do evento cumpre apenas o papel de incentivar atores racionais a perseguirem sua manutenção.

A nosso ver, contudo, a complementaridade entre uma abordagem funcional de um dado fenômeno e sua explicaşão intencional não precisa seguir a sugestão de que os agentes envolvidos estejam conscientes dos benefícios produzidos pelo evento que se quer explicar. Basta que a funcionalidade seja constatada pelo analista e que a reprodução do fenômeno em questão seja explicada em termos de condutas individuais, ainda que não intencionalmente orientadas pela busca de efeitos benéficos.

Voltando ao exemplo, o analista pode, num primeiro momento, revelar como o racismo pro- 
duz efeitos funcionais para a dominação de classe e, num segundo momento, mostrar que tal fenômeno se mantém não porque alguns membros da classe dominante incentivem conscientemente a produção de tais efeitos, mas sim porque existem atores sociais que orientam a sua conduta em função de uma visão racista de mundo adquirida ao longo de um processo de socialização estável. Nesse caso, o racismo teria uma "disposição" para ser funcional para uma sociedade dividida em classes, mas sua gênese e persistência não precisariam ser explicadas por essa funcionalidade.

Evidentemente, nada disso exclui a possibilidade de que haja uma percepção dos benefícios que o racismo produz para a dominação social e que isso gere uma busca consciente de sua permanência. Mas isso não é absolutamente necessário para que a abordagem funcional - isto é, a constatação da funcionalidade do racismo para a reprodução da dominação de classe por meio da divisão étnica da classe dominada - e a explicação intencional - isto é, a identificação das motivações subjetivas que estão na base de ações sociais que contribuem para a produção e a reprodução do fenômeno do racismo sejam executadas conjuntamente.

\section{(iii) A explicação funcional como um "trabalho preliminar"}

O funcionalismo que pretende identificar regularidades, mas não explicar a gênese de um fenômeno pelas suas consequiências, é definido por Giddens como um "funcionalismo sofisticado", ao qual cabe, na verdade, apenas a realização de um trabalho preliminar que demandaria posteriormente mais esforço analítico. Ou seja, esse trabalho preliminar serviria para indicar fenômenos que "clamam por explicações, em vez de serem explicados pelas concepções que eles [os funcionalistas] oferecem" (Giddens, 1982, p. 531).

É preciso, porém, evitar o menosprezo ante esse "trabalho preliminar". Pensamos que, seguindo as indicações de Cohen, a identificação de regularidades é uma forte indicação da direção em que deve caminhar a pesquisa, além de, por si só, revelar ligaçōes interessantes e significativas. É o que sugere o próprio Weber, ao dizer que
[...] necessitamos saber primeiro qual é a importância de uma ação do ponto de vista funcional para a "conservação" [...] e o desenvolvimento em uma direção determinada de um tipo de ação social antes de poder nos perguntar de que maneira se origina aquela ação e quais são os seus motivos. É preciso que saibamos quais serviços prestam um "rei', um "funcionário", um "empresário", um "rufiāo", um "mago"; ou seja, que ação típica [...] é importante para a análise e merece ser considerada antes de começarmos a análise propriamente dita (Weber, [1922] 1984, p. 15, grifo nosso).

A conclusão de Elster pela expulsão da abordagem funcional do campo da teoria social mostra-se, portanto, claramente como um exagero. Contudo, é inegável que esse tipo de explicação não é capaz de fornecer os mecanismos dos fenômenos que procura explicar. É essa, a nosso ver, a parte mais importante da crítica de Elster ao tipo funcional de explicação.

Se essa é a parte mais importante, substantiva e fecunda da crítica de Elster à explicação funcional e, por consequiência, ao marxismo tradicional, então pode-se compreender melhor a natureza do seu projeto intelectual em particular e o dos marxistas analíticos em geral. Trata-se de fornecer ao marxismo um instrumental que lhe permita detectar mecanismos, o que, na perspectiva dos analíticos, deve ser feito por meio da adoção do instrumental teórico da teoria econômica neoclássica. É o que veremos a seguir.

\section{Individualismo, racionalidade e teoria dos jogos}

$\mathrm{O}$ individualismo metodológico, a teoria da escolha racional e a teoria dos jogos seriam as "ferramentas" que possibilitariam ao marxismo vencer o vazio explicativo da explicação funcional. Esse instrumental metodológico permitiria acessar os mecanismos ocultos de todo e qualquer fenômeno social que se queira explicar. Explicar um determinado fenômeno social, do ponto de vista do marxismo analítico, não é relacioná-lo às conse- 
qüências benéficas que gera para um determinado grupo; não é encaixar o fenômeno numa concepção teleológica de história em que tudo se explica pelo que deve necessariamente acontecer no futuro; não é submeter o fenômeno em questão aos "papéis históricos" que ele deve cumprir ou aos "interesses de classe" previamente estabelecidos que ele deve atender. Explicar é fornecer os microfundamentos (os mecanismos) do fenômeno social em questão. ${ }^{7}$

\section{(i) O individualismo metodológico ${ }^{8}$}

A idéia básica do individualismo metodológico é que, em última instância, quem age não são "as classes", "o Estado", "os grupos sociais”, mas os indivíduos. São eles os responsáveis pelas ações e, portanto, pelos fenômenos sociais. Assim, é preciso estudar esses fenômenos a partir das motivações individuais para a ação. A ação coletiva, por exemplo, tão comum nas sociedades contemporâneas, não pode ser entendida a partir de categorias coletivas abstratas, mas apenas em função de um agregado de comportamentos individuais. Captar o mecanismo de um fenômeno social e revelar os seus microfundamentos significa exatamente revelar as crenças e as motivaçôes que levam os indivíduos a agir e mostrar como eles agiram de fato, dando origem ao fenômeno que se pretende estudar.

A proposta de abordar os fenômenos sociais a partir dos comportamentos individuais é instigante, sobretudo se a entendermos como uma crítica ao "coletivismo metodológico" marxista. Para Elster, não é possível explicar os fenômenos sociais a partir da idéia de "classe", "interesse de classe", "capital" e "Estado", por exemplo. Na verdade, essas entidades, assim pensadas, não existem. Quando falamos que um Estado tomou esta ou aquela decisão, que uma classe deseja tal coisa ou que uma nação almeja um dado fim, estamos, na verdade, adotando uma maneira taquigráfica de dizer que determinados indivíduos pertencentes a essas diversas instituições ou grupos se mobilizaram para realizar tais objetivos. Portanto, é no âmbito do comportamento individual que devemos compreender tais realidades coletivas.

Como se percebe, não há nada de original nessas proposições, que já podem ser encontradas nos diversos escritos metodológicos de Max Weber, em particular nos "fundamentos metodológicos" do seu Economia e sociedade. Acerca do caráter excessivamente abstrato dessas entidades coletivas, vale a pena reproduzir aqui a seguinte citação:

Para a sociologia, a realidade "Estado" não consiste apenas nem necessariamente nos seus elementos jurídicos relevantes. Para a sociologia não existe uma personalidade coletiva em ação. Quando se usam os termos "Estado", "Nação", "sociedade anônima", "família", "corpo militar" ou quaisquer formações sociais semelhantes, ela se refere exclusivamente ao desenvolvimento [...] da ação social por alguns indivíduos, seja ela real seja constituída como possível (Idem, p. 12, grifo nosso).

Portanto, o marxismo analítico, por intermédio do individualismo metodológico, faz parte daquela estratégia dentro das ciências sociais que consiste na recuperação do "ator", recolocando-o no centro dos fenômenos sociais e, por conseguinte, no centro das explicaçôes sociológicas. No entanto, e é preciso deixar isso bem claro, o marxismo analítico não defende o retorno das ciências sociais a um subjetivismo delirante que desprezaria as determinações objetivas da ação. Pensamos que essa afirmação ficará mais clara ao abordarmos a proposta de conjugar marxismo e teoria da escolha racional.

\section{(iii) A teoria da escolha racional}

A teoria da escolha racional tem um postulado básico, segundo o qual os indivíduos são racionais, isto é, em situaçôes de escolha eles escolherão a alternativa que maximizará as vantagens que se pretende obter. Esse pressuposto é tão forte que Roemer não hesita em definir a teoria da escolha racional como um método dedutivo, ou seja, um método que "procura deduzir observações históricas a partir de postulados básicos sobre o comportamento individual que são suficientemente fundamentais para serem considerados evidentes em si" (Roemer, 1982, p. 514).

No entanto, se, de acordo com a teoria da escolha racional, os indivíduos são capazes de fazer 
opções racionais em situações de escolha, isso não significa que eles tenham plena liberdade de ação. $\mathrm{Na}$ verdade, essas situações de escolha são vivenciadas pelos atores sociais por meio de dois "filtros", filtros estes que revelam como a teoria da escolha racional confere importância às condições objetivas. Os dois filtros são, com efeito, processos de exclusão que acabam por condicionar a alternativa que deverá ser escolhida.

O primeiro filtro é exatamente o que poderíamos chamar de "filtro objetivo". Ele impóe a exclusão dos cursos de ação que não satisfazem critérios lógicos, físicos, econômicos ou mentais. Todos esses elementos objetivos, isto é, que não dependem da vontade do indivíduo, são constrangimentos às decisões individuais.

O segundo filtro refere-se exatamente à dimensão subjetiva do processo de escolha, isto é, à escolha racionalmente feita pelo indivíduo. $\mathrm{O}$ primeiro deixa um conjunto de ações remanescentes que devem ser avaliadas pelos indivíduos a partir de um determinado critério de seleção. A teoria da escolha racional diz que, numa situação como essa, os indivíduos escolherão o curso de ação que preferirem ou que acreditarem ser o melhor em função dos objetivos a serem atingidos. Assim, agir racionalmente significa escolher a melhor opção num conjunto de opções viáveis.

Ao levar em consideração esses dois filtros da escolha individual pretende-se combinar as considerações predominantemente subjetivistas da teoria econômica neoclássica com as inclinaçôes objetivistas do marxismo (Roemer, 1989, pp. 224226).$^{10}$ Elster, contudo, afirma que é preciso insistir no aspecto subjetivo da escolha, pois o fato de que opções estejam objetivamente disponíveis para um agente não pode entrar na explicação de seu comportamento se ele não tem bases racionais, isto é, evidências e informações para saber que essas alternativas estão disponíveis. Aqui se percebe o individualismo metodológico sendo operacionalizado. Uma vez cumpridas as determinações objetivas do primeiro filtro, o elemento determinante da ação não é a existência objetiva de possibilidades, mas a crença e o desejo do indivíduo em realizá-las e a sua capacidade de percebê-las como viáveis e adequadas a seus objetivos. Uma ação só se efetiva porque o individuo é capaz de percebê-la racionalmente como uma alternativa e porque suas crenças e desejos o motivam a agir. ${ }^{11}$

A teoria da escolha racional é particularmente importante para pensar um problema central para o marxismo, a saber, as ações coletivas. A teoria da escolha racional reconhece a importância das condiçôes externas partilhadas por vários indivíduos, já que elas são fundamentais para a formação de crenças e desejos similares que, por sua vez, podem gerar um impulso para a solidariedade. No entanto, essa teoria rejeita qualquer procedimento intelectual que, a partir das condições de existência e de crenças e desejos partilhados por determinados indivíduos, deriva automaticamente um ator social coletivo dotado de vontade própria e com uma consciência política determinada. A grande contribuição da teoria da escolha racional para a sociologia foi tomar a ação coletiva como um problema a ser explicado e não como um fato inerente às condições objetivas de um dado grupo. Nesse sentido, não se pode pressupor, mas é preciso explicar como a "solidariedade" (uma forma de pensar e sentir em conjunto) se traduz efetivamente em "cooperação" (uma forma de fazer em conjunto) (Kaplan e Lasswell, 1998, pp. 60-61).

Mancur Olson, em A lógica da ação coletiva, revela que um dos erros das teorias que lançam mão da ação coletiva para explicar os fenômenos sociais e políticos é pressupor que a lógica da conduta individual se aplica também à ação coletiva. Essas teorias, inclusive o próprio marxismo, parecem admitir que se um indivíduo isolado e consciente de seus interesses persegue seus objetivos racionalmente, então vários indivíduos diante de uma situação semelhante, percebendo a similaridade de seus interesses, agirão coletivamente para realizá-los da melhor forma possível. Como mostra Olson, se mantivermos o pressuposto da racionalidade individual, perceberemos que, em grandes grupos, a saída mais racional é sempre a abstenção, frustrando-se, assim, o surgimento voluntário de açôes coletivas nesses grupos. Dessa forma, a classe estaria impedida de se transformar, diretamente, num ator coletivo (Olson, 1999). Sendo a classe social uma categoria analítica fundamental para a teoria política marxista, tais observações não podem ser simplesmente 
ignoradas, pois dizem respeito à possibilidade (ou impossibilidade) de utilizar tal categoria para a análise política.

A constatação de que há uma incompatibilidade inicial entre racionalidade individual $\mathrm{e}$ a produção de benefícios públicos (isto é, entre racionalidade individual e estratégias voluntárias de solidariedade) é muito importante para o marxismo, porque o próprio Marx confere a esse tipo de conduta um lugar importante nas suas consideraçōes sobre o capitalismo (Boudon, 1993, pp. 195-196; Maguire, 1984, cap. V). Se essa observação pode parecer um tanto quanto temerária para uma obra como $O$ capital, nas obras históricas, tais como O 18 brumário de Louis Bonaparte, a Luta de classes em França e os escritos da Nova Gazeta Renana, a presença de um modelo estratégico de ação para entender a dinâmica política desses contextos históricos salta aos olhos.

Em suas análises, Marx refere-se com freqüência às classes sociais como atores coletivos que agem diretamente na cena política ou são intermediados por organizaçôes ou agentes que as representam, tais como os partidos, os políticos profissionais, as agências estatais ou os líderes pessoais. No entanto, nunca sabemos ao certo exatamente como a classe age ou como se dá a relação de representação entre elas e seus supostos representantes. Certamente, há várias observaçōes e insights instigantes nas análises de Marx. No entanto, dada a centralidade do conceito de classe para a teoria marxista, não é mais possível limitar a análise classista da política a observaçôes vagas e metafóricas. Ao contrário, é preciso pensar uma teoria e uma metodologia que permitam aos marxistas efetivamente explicar como (e se) as classes se organizam, agem e se tornam capazes de transformar a realidade social. Uma evidência indireta das dificuldades que esse problema coloca é o fato de o marxismo contemporâneo praticamente se abster de discutir o problema da classe social como ator político coletivo. "A ausência de uma teoria adequada de capacidade de classe constitui uma fraqueza importante do materialismo histórico, especialmente em suas aplicaçôes à sociedade capitalista" (Wright, Levine e Sober, 1993, p. 70). ${ }^{12}$

\section{(iii) A teoria dos jogos}

A teoria dos jogos é um complemento das duas primeiras estratégias analíticas apresentadas anteriormente. $\mathrm{O}$ seu objeto de estudo são situações de interdependência de decisôes racionais, ${ }^{13}$ nas quais o ator percebe que a ação dos outros agentes necessariamente influi no curso da sua própria ação.

Essa interdependência das ações é vista pela teoria dos jogos a partir de duas perspectivas: a dos jogos não cooperativos e a dos jogos cooperativos. Os primeiros são de soma-zero, isto é, jogos em que se um dos agentes ganha, o outro necessariamente perde na mesma proporção. São, por essa razão, jogos de conflito puro, que anulam as possibilidades de cooperação. Ao contrário, os jogos cooperativos são de soma variável, nos quais as estratégias escolhidas pelos agentes afetarão também o total a ser dividido. Por essa razão, eles podem misturar o conflito com a cooperação. Vale insistir, no entanto, que é preciso que os agentes racionais envolvidos nessas interaçóes percebam as situações como sendo de conflito ou de cooperação para que elas se desenvolvam em direção ao enfrentamento ou à solidariedade. Tal percepção é influenciada por um sem-número de variáveis, tais como os processos de socialização, a quantidade e a qualidade das informações à disposição dos agentes e os seus recursos cognitivos.

Um exemplo de jogo cooperativo é exatamente a relação entre capitalistas e trabalhadores. Nesse jogo, a soma é variável porque a acumulação de capital pode crescer efetivamente. Assim, uma situação de conflito em que, de um lado, os trabalhadores exigem aumento salarial e, de outro, os capitalistas se recusam a concedê-lo, pode ser resolvida se o aumento salarial for concedido a partir do aumento da produtividade (isto é, do aumento da extração de mais-valia relativa). Desse modo, capitalistas e trabalhadores podem chegar a uma situação de cooperação exatamente porque a variação da soma total permitiria ganhos de lado a lado. Em grande parte, é isso que nos impede de afirmar que o conflito entre capitalistas e trabalhadores levará necessariamente a um impasse, e conseqüentemente, ao socialismo. Segundo Elster, quando Marx fazia essa previsão, encarava o jogo entre capitalistas e trabalhadores, erroneamente, como um jogo de soma-zero. 


\section{Conclusão}

Há, evidentemente, diversas críticas já feitas às formulações dos marxistas analíticos e, sobretudo, à sua proposta de aproximar o marxismo do instrumental metodológico da teoria econômica neoclássica, além de críticas à essência mesma desse instrumental. Gostaríamos, entretanto, de insistir no pecado maior, cometido lá e cá, que consiste na busca da "pureza metodológica", para usar a expressão de Berger e Offe (1982).

A insistência de Jon Elster, em texto publicado na revista Theory and Society, no uso exclusivo do individualismo metodológico, da teoria da escolha racional e da teoria dos jogos para analisar a conduta humana parece-nos, de fato, empobrecer o processo de conhecimento dos processos sociais. Dessa forma, acreditamos que essa proposta deve ser sempre acompanhada de uma análise estrutural sofisticada (isto é, que não veja a estrutura social apenas como um "impedimento"), já que é simplesmente impensável não supor a existência de determinações desse tipo sobre a conduta dos atores sociais. Como argumentam Berger e Offe,

Logicamente, o jogo começa apenas depois que os atores foram constituídos, e as suas ordens de preferências são formadas como um resultado de processos que não podem ser considerados eles mesmos como partes do jogo. Ao contrário, limites como os recursos disponíveis, a capacidade de aprender, as prioridades e os custos dos modos alternativos de comportamento estratégico devem ser explicados por outra teoria que não a da "escolha racional". Nesse sentido, confiar exclusivamente na teoria dos jogos para explicar, eliminando importantes elementos constituidores e psicocondições do jogo, não apenas da agenda metodológica, mas também da agenda sociológica, é pagar um preço alto demais pela pureza metodológica, para os cientistas sociais em geral e para os marxistas em particular (Idem, p. 525, grifo nosso).

No entanto, a busca da pureza metodológica é um pecado que também acomete o outro lado da disputa. Para Cohen, por exemplo, não há nada mais incompatível com o marxismo do que adotar a estratégia sugerida por Elster. Para ele, o coração do materialismo histórico reside nas grandes conexões explicativas, estabelecidas por Marx e sistematizadas no "Prefácio" de 1859, entre forças produtivas e relações de produção. Esse núcleo central do marxismo comporta ainda um corolário inescapável: a afirmação da tese de que a superestrutura da sociedade serve para a estabilização da sua estrutura econômica. Sendo assim, Elster deveria escolher: ou individualismo metodológico ou marxismo (Burawoy, 1989, p. 63).

Para evitarmos as armadilhas da pureza metodológica, acreditamos, sim, que vale a pena incorporar algumas das críticas e sugestões elaboradas pelos analíticos, pois elas fortaleceriam o marxismo como ciência social. Nesse sentido, três pontos são particularmente importantes a nosso ver.

\section{(i) As críticas à explicação funcional}

Parece-nos irrefutável que explicações funcionais pouco sofisticadas, notadamente aquelas que pretendem explicar a gênese de um fenômeno pela suas conseqüências, devem ser definitivamente abandonadas em função de sua incoerência lógica. Mesmo as proposições mais sofisticadas, porém, quase sempre cometem o pecado de transformar a constatação de conexôes funcionais em explicações causais, sem que, de fato, os mecanismos causais dessa conexão sejam demonstrados. Limitam-se, quase sempre, a fazer referências a uma suposta "necessidade sistêmica" ou aos "imperativos da função objetiva" que, como vimos, nunca se sabe ao certo como funcionam.

Entretanto, apesar da validade dessas críticas, pensamos ser possível continuar trabalhando com a abordagem de tipo funcional, sobretudo se a entendermos como uma análise exaustiva de processos empíricos que identifica conexôes funcionais poderosas e, assim, cumpre um importantíssimo trabalho preliminar à explicação propriamente dita.

\section{(ii) Aspecto empírico da primazia causal}

Parece-nos também correto dizer que a identificação de conexões funcionais, por mais regulares 
que sejam, não nos autoriza, por si só, a estabelecer uma primazia causal. $\mathrm{O}$ fato de que uma determinada forma de Estado $(A)$ seja funcional para as relações de produção $(B)$ não é suficiente para estabelecer a primazia causal do econômico $(B)$ sobre o político $(A)$. Tal observação é ainda mais importante para um marxismo mais sofisticado, que claramente confere às "superestruturas" um papel muito ativo. Sendo assim, é preciso desenvolver procedimentos metodológicos, recursos analíticos, conceitos operacionais que permitam verificar empiricamente essa primazia causal, em vez de transformá-la num postulado doutrinário.

Para Wright, Levine e Sober (1993, pp. 223 e 245), afirmaçôes fundamentadas sobre primazia causal só podem ser feitas com efetiva segurança em pesquisas de natureza quantitativa, isto é, que permitam a mensuração das variáveis. Essas pesquisas, porém, sofrem de dois problemas. $\mathrm{O}$ primeiro, observado pelos próprios autores, refere-se ao fato de que pesquisas quantitativas adotam um modelo aditivo de causalidade, isto é, limitam-se a detectar o peso de cada causa isoladamente na produção do efeito que se quer explicar. São, portanto, de difícil aplicação quando se pretende analisar a articulação contextual entre várias causas. O segundo problema, acrescentamos, é que não raro tais pesquisas, a fim de viabilizarem a medição, cometem tantas agressões à realidade que, ao fim e ao cabo, não sabemos se elas dizem algo sobre o mundo real ou apenas sobre o banco de dados que construíram.

No entanto, é inegável que as afirmações sobre primazia causal em pesquisas qualitativas são sempre mais incertas, dadas a complexidade do objeto e a pretensão de ver causas articuladas contextualmente em vez de simplesmente justapostas umas às outras. Uma das maneiras de ter maior controle sobre a complexidade do mundo social sem deturpá-la é por meio do uso do método comparativo. Este método parece ser uma maneira razoavelmente segura de estabelecer atribuições causais, e já há um bom tempo vem sendo submetido a uma crescente discussão para torná-lo mais rigoroso (Ragin, 1987). Ainda assim, quem adotar a estratégia de pesquisa qualitativa deve sentir-se pouco seguro para fazer generalizações absolutas sobre relaçôes causais. ${ }^{14}$ $\mathrm{O}$ método comparativo parece ser particularmen- te pertinente para o procedimento indutivo de um marxismo à la Cohen, cujo objetivo é identificar conexôes funcionais historicamente regulares.

De qualquer forma, aqui também seria preciso evitar uma confusão recorrente. Como vimos, a constatação de uma conexão funcional entre dois fenômenos não representa, ao mesmo tempo, a formulação de uma relação causal. Ou seja, o fato de que $Y$ é funcional para $Z$ não nos revela a causa de $Y$. Por sua vez, a identificação de uma relação causal por meio do método comparativo não pode ser confundida com a elaboração de uma explicação causal. A descoberta de que $X$ causa $Y$ nada nos diz sobre como exatamente $X$ causa $Y$. Como lembra Stuart Mill, o processo de identificação da causa nada tem a ver com o desvendamento do "modo de produção do fenômeno" (Stuart Mill, 1886, p. 213). Ou, por outro lado, conexão funcional, relação causal e explicação causal são três coisas distintas. Nesse sentido, como sustentaram os marxistas analíticos, somente a identificação dos "mecanismos", isto é, da cadeia de ações e estratégias individuais, poderia abrir a "caixa-preta" e efetivamente vincular a causa ao efeito, isto é, somente ela poderia fornecer uma explicação de tipo causal.

\section{(iii) O problema da ação coletiva}

Há importantes contribuições no que diz respeito a formas alternativas de pensar o problema fundamental da ação coletiva. Para o marxismo analítico, as entidades coletivas tradicionalmente operacionalizadas pelas explicações marxistas - o Estado, as classes, o capital etc. - são demasiadamente abstratas e, por isso, pouco explicativas. Atribui-se a essas entidades interesses e papéis históricos previamente definidos, aos quais os comportamentos efetivos dos agentes devem se adequar funcional e teleologicamente. A questão, como dissemos, parece-nos particularmente importante para recolocar a ação de classe no centro das preocupações teóricas do marxismo.

Por fim, mesmo que pareça restar tão pouco do marxismo na proposta em questão, é importante dizer que o marxismo analítico não se identifica tão intimamente com a teoria econômica neoclássica como se pode pensar. Seus principais representan- 
tes continuam a sustentar um compromisso com a maleabilidade histórica das preferências humanas, em função da formação social do indivíduo, enquanto para os neoclássicos as preferências são frutos de uma natureza humana imutável que define o mundo objetivo. $\mathrm{O}$ marxismo analítico insiste na importância da ação coletiva e da relação de poder entre os “atores", enquanto os neoclássicos têm uma interpretação puramente individualista, da qual está ausente qualquer idéia de dominação. Eles defendem um "materialismo mitigado" (Wright, Levine e Sober, 1993, p. 160) que considera altamente plausível a tese da determinação materialista para alguns processos sociais (mas não para todos), desde que submetidos ao teste da pesquisa empírica. Enfim, o marxismo analítico crê na injustiça do capitalismo, na sua transitoriedade histórica e, por conseguinte, no projeto de emancipação contido no marxismo, não havendo, é claro, nada nesse sentido na teoria neoclássica (Roemer, 1989, p. 230).

\section{Notas}

1 Para um resumo dos temas abordados e dos modos de abordagem, ver Romer (1989). Ver também, Przeworsky (1989) e Wright (1985). Entretanto, considerar o marxismo analítico como uma "escola" pode sugerir uma unidade de pensamento mais intensa do que a que efetivamente existiu. Como veremos a seguir, a unidade desta "escola" residia fundamentalmente em dois pontos: a) conferir maior clareza às formulações causais do marxismo clássico, de acordo com os procedimentos da filosofia analítica, e b) negar qualquer especificidade metodológica ao marxismo. Fora desse terreno comum, existiam muitas divergências. Talvez a mais significativa seja a crítica de Jon Elster à explicação funcional e à sua inteira adesão ao individualismo metodológico, posições radicalmente contrárias às de G. A. Cohen, fundador do grupo. Cf. Tarrit, 2006.

2 Elster apresentou posições mais moderadas em entrevista posterior. Cf. Elster, 1991, pp. 98-99. Poderíamos resumir seu pensamento da seguinte maneira: “1) Uma das maneiras de ler um mapa das motivações humanas seria classificando-as da seguinte forma: às vezes, as pessoas perseguem seus objetivos agindo racionalmente; outras, impulsionadas por suas emoçôes; outras tantas, seguindo as normas sociais. A ação racional tem prioridade porque com maior freqüên- cia procuramos agir racionalmente; 2) É necessário incorporar às ciências sociais, cada vez mais, a busca pela compreensão do comportamento não racional, partindo do suposto de que tais comportamentos não são residuais e devotando especial atenção às contradições mentais relativas a esse tópico; 3) Normas sociais, cultura, emoçóes e racionalidade podem e devem ser entendidas nos termos do individualismo metodológico" (Ratton Jr. e Ventura de Morais, 2003, p. 387). Nesse sentido, o leitor talvez concluísse, e o faria com razão, que ganharíamos muito se fechássemos os livros de Jon Elster e voltássemos a abrir os de Max Weber.

3 É importante observar que a explicação funcionalista, onde quer que tenha sido aplicada de forma mais sofisticada, nunca pretendeu explicar a gênese dos fenômenos e das instituições sociais, mas sim seus efeitos objetivos para a reprodução do sistema social e, por meio desses efeitos, a durabilidade ou a persistência de tais fenômenos. Cf. Durkheim (1984, pp. 35-42, 6364 e 79-80) e Merton (1967, pp. 104-108).

4 Cf. Weber, [1922] 1984, pp. 5 e 11. Sobre a relação entre "compreensão" e "explicação" em Weber, ver Ringer, 1997, pp. 13-17. Segundo Boudon, os efeitos perversos são "efeitos individuais ou coletivos que resultam da justaposição de comportamentos individuais e que não fazem parte dos objetivos perseguidos pelos atores" (Boudon, 1993, p. 10). Em resumo, na sociologia de orientação individualista, "explicações intencionais são geralmente acompanhadas da procura de conseqüências não intencionais (os chamados 'efeitos de agregação') nas ações intencionais das pessoas. Ao contrário de formas funcionalistas de explicação, as conseqüências não intencionais das práticas sociais não são empregadas para explicar a persistência das mesmas práticas" (Baert, 1998, p. 3).

5 Não por outra razão, Wright, Levine e Sober, ao comentarem o conceito de "fato disposicional", conferem, muito mais do que Cohen, um lugar central à intenção dos atores na sua produção e acabam por reconhecer que "é certamente difícil defender empiricamente proposiçôes sobre fatos disposicionais" (Wright, Levine e Sober, 1993, p. 119).

6 Quanto a este ponto, ver também Roemer (1982, pp. 513-514) e Cohen (2001, p. 287).

7 "Explicações por mecanismos" podem ser assim descritas: 1) devem ser baseadas em ações, isto é, os atores e não as variáveis são os agentes. Portanto, não podem ser formuladas sobre meras associações entre variáveis, mas devem fazer referência direta às causas e às conseqüências da ação individual voltada para o 
comportamento de outros atores; 2) devem buscar precisão elucidativa. Em outras palavras, não devem estar situadas em tal nível de teorização que implique indeterminação explicativa, nem devem tentar estabelecer leis sociais gerais, improváveis de existirem no domínio da sociologia; 3) necessitam, contudo, de um grau de abstração mínimo que permita a seleção dos fatores relevantes para a construção de modelos formulados de maneira a incluir somente elementos que se acredita serem essenciais; 4) devem abrir a "caixa-preta" e tornar claro o que liga a causa ao efeito. Cf. Ratton Jr. e Ventura de Morais, 2003, pp. 9-11.

8 É muito importante diferenciar, e tratar separadamente, o individualismo metodológico da teoria da escolha racional, porque não raro ambos são apresentados como sinônimos por alguns autores do marxismo analítico. Enquanto o individualismo metodológico reconhece a existência de outros tipos de ação social e o caráter histórico da racionalidade instrumental, a teoria da escolha racional comporta apenas um tipo de ação e tende a universalizar (isto é, a desistoricizar) a racionalidade estratégica. Cf., por exemplo, Carvalho, 2008, pp. 160-161.

9 Os teóricos da escolha racional reconhecem, porém, que nada têm a dizer sobre como se formam as preferências a partir das quais as escolhas são feitas (cf. Elster, 1982, p. 465, n. 46; Becker, 1990, p. 5). Esse reconhecimento, entretanto, revela um dos pontos mais frágeis da aplicação da teoria da escolha racional aos problemas sociológicos. Do ponto de vista do sociólogo, muito mais importante (e interessante) do que identificar as estratégias maximizadoras de um determinado fim é saber por que os agentes perseguem um fim determinado e não outro qualquer. Nesse sentido, o sociólogo teria razão em dizer que o adepto da teoria da escolha racional troca o principal pelo acessório.

10 Um estruturalista mais radical diria que temos aqui uma concepção muito limitada acerca do papel das estruturas sociais na determinação da conduta humana. Diria que as estruturas sociais não cumprem apenas um papel negativo (limite objetivo) em relação à conduta humana; elas cumprem também o papel positivo de fornecer os meios (materiais e simbólicos) para a ação. As estruturas não definiriam apenas o conjunto de opções viáveis a disposição do ator, mas, em grande medida, a própria escolha. Com relação a esse ponto, ver Giddens (1994, p. 51), Foucault (2002, pp. 2628) e Bourdieu (1989).

11 Para um resumo dos atributos essenciais da teoria da escolha racional, consultar Tsebellis (1998) e Downs
(1999). Para uma visão crítica, ver Baert (1998) e Carvalho (2008).

12 Discutimos esse ponto mais extensamente em Perissinotto (2007). Sobre a relação entre classe social e ação coletiva no marxismo analítico, ver também Reis (1991). Este último trabalho é particularmente interessante por mostrar como a aceitação da tese de Olson acerca da indeterminação da conduta política de uma classe social impõe refutar também qualquer definição desse conceito que inclua elementos referentes à "classe-para-si". Nesse sentido, defende-se uma tese próxima a de G. A. Cohen, para quem "A classe social de uma pessoa é definida exclusivamente pelo seu lugar objetivo na rede de relações de propriedade, por mais difícil que seja identificar tal lugar claramente. Sua consciência, cultura e sua prática política não entram na definição de sua posição de classe. Na verdade, essas exclusōes são necessárias para proteger o caráter substantivo da tese marxiana de que a posição de classe condiciona fortemente a consciência, a cultura e a prática política" (Cohen, 2001, p. 73).

13 Para Elster, uma melhor denominação para a teoria dos jogos seria exatamente "teoria das decisões interdependentes" (1989b, p. 41).

$14 \mathrm{O}$ mais clássico exemplo de prudência quanto a esse ponto é a recusa de Max Weber de transformar a causa mais relevante para a ocorrência de um dado fenômeno em "causa necessária" desse mesmo fenômeno, preferindo a expressão "causa adequada". Para Weber, a sociologia e a história comparada, desde que conjugadas, podem identificar causas relevantes passíveis de alguma generalização, mas são incapazes de estabelecer relações causais universais, como fazem as ciências da natureza, exatamente em função da maior complexidade de seus objetos (cf. Max Weber, 2004).

\section{BIBLIOGRAFIA}

ALTHUSSER, Louis. (1970), "El objeto de 'El capital", in _. Para leer El capital, Mexico, Siglo XXI.

BAERT, Patrick. (1998), "Algumas limitações das explicaçôes da escolha racional na ciência política e na sociologia". Revista Brasileira de Ciências Sociais, 12 (35): 63-74, out.

BECKER, Gary S. (1990), The economic approach to human behavior. Chicago, The University of Chicago Press. 
BERGER, Johannes \& OFFE, Claus. (1982), "Functionalism vs rational choice? Some questions concerning the rationality of choosing one or the other". Theory and Society, 11 (4): 521-526.

BOUDON, Raymond. (1993), Effets pervers et ordre social. Paris, Quadrige/Presse Universitaire de France.

BOURDIEU, Pierre. (1989), "A gênese dos conceitos de habitus e de campo", in O poder simbólico, Lisboa, Difel, pp. 59-73.

BURAWOY, Michael. (1989), "Making nonsense of Marx: le marxisme revu par l'individualisme méthodologique". Actes de la Recherche en Sciences Sociales, 78 : 61-63, juin.

CARVALHO, Bruno Sciberras de. (2008), A escotha racional como teoria social e politica: uma interpretação crítica. Rio de Janeiro, Topbooks.

COHEN, G. A. (1982), "Reply to Elster on 'Marxism, functionalism, and game theory". Theory and Society, 11 (4): 483-495.

(1989), "El marxismo y la explicación functional", in J. E. Roemer (org.), El marxismo: una perspective analitica, México: Fondo de Cultura Económica, pp. 252-266.

(2001), Karl Marx's theory of history: a defense. New Jersey, Princeton University Press.

DOMENĖCH, Antoni. (2009), "Qué fue del 'marxismo analítico'? (En la muerte de Gerald Cohen)". Revista Sin Permiso, 6. Disponível em <www.sinpermiso.info>.

DOWNS, Anthony. (1999), Uma teoria econômica da democracia. São Paulo, Edusp.

DURKHEIM, Émile. (1984), A divisão do trabalho social. Lisboa, Editorial Presença.

ELSTER, Jon. (1982), "Marxism, functionalism, and game theory". Theory and Society, 11 (4): 453-482.

Blackwell.

. (1986), Rational choice. Londres, Basil

. (1989a), "Reflexiones sobre marxismo, funcionalismo y teoria de los juegos", in J. E. Roemer (org.), El marxismo: uma perspectiva analítica, México, Fondo de Cultura Económica, pp. 231-251.

. (1989b), Marx hoje. Rio de Janeiro, Paz e Terra. (1989c), Ulises y las sirenas: estudios sobre racionalidad e irracionalidad. México, Fondo de Cultura Económica.

. (1991), "Marxismo analítico: o pensamento claro. Uma entrevista com Jon Elster”. Novos Estudos Cebrap, 31: 95-106.

ENGELS, Friedrich. (s/d.), "Ludwig Feurbach e o fim da filosofia clássica alemã" [1888], in Karl Marx e Friedrich Engels: obras escolhidas, São Paulo, Alfa-Ômega, vol. 3, pp. 169-207.

FOUCAULT, Michel. (2002), Vigiar e punir. Petrópolis, Vozes.

GIDDENS, A. (1994), Central problems in social theory: action, structure and contradiction in social analysis. Berkley, University of California Press.

GIDDENS, Anthony. (1982), "Commentary on the debate". Theory and Society, 11 (4): 527 539.

KAPLAN, A. \& LASSWELL, H. (1998), Poder e sociedade. Brasília, Editora da Unb.

LIPIETZ, Alain. (1991), "As crises do marxismo". Novos Estudos Cebrap, 30: 99-110.

LUKÁCS, Georg. ([1919] 1974a), "A consciência de classe", in , História e consciência de classe: estudos de dialética marxista, Lisboa, Publicações Escorpião, pp. 59-96.

. ([1919] 1974b), "O que é o marxismo

ortodoxo?", in , História e consciência de classe: estudos de dialética marxista, Lisboa, Publicações Escorpião, pp. 15-40.

MAGUIRE, John M. (1984), Marx y su teoria de la política. México, Fondo de Cultura Econômica.

MARX, Karl. ([1852] 1984), O 18 brumário de Louis Bonaparte. Lisboa, Avante.

. ([1848] 1989), "La burguesia y la contrarrevolución”, in , Las revoluciones de 1848, México, Fondo de Cultura Económica, pp. 213-233.

MERTON, Robert K. (1967), On theoretical sociology: five essays, old and new. Nova York, Free Press.

(1979), A ambivalência sociológica. Rio de Janeiro, Zahar.

OLSON, Mancur. (1999), A lógica da ação coletiva. São Paulo, Edusp. 
PERISSINOTTO, Renato M. (2007), "O 18 brumário e a análise de classe contemporânea”. Lua Nova - Revista de Cultura e Politica, 71: 81-122.

POULANTZAS, Nicos. (1986), Poder politico e classes sociais. São Paulo, Martins Fontes.

PRZEWORSKY, Adam. (1989), Capitalismo e social-democracia. São Paulo, Companhia das Letras.

RAGIN, Charles C. (1987), The comparative method: moving beyond qualitative and quantitative strategies. Los Angeles, University of California Press.

RATTON JR.; Amorim, José Luiz de \& VENTURA DE MORAIS, Jorge. (2003), "Para ler Jon Elster: limites e possibilidades da explicação por mecanismos nas ciências sociais”. Dados, 46 (2): 385-410.

REIS, Bruno P. W. (1991), "O conceito de classes sociais e a lógica da ação coletiva”. Dados, 34 (3): 415-451.

RINGER, Fritz. (1997), A metodologia de Max Weber: unificação das ciências culturais e sociais. São Paulo, Edusp.

ROEMER, John E. (1982), "Methodological individualism and deductive marxism". Theory and Society, 11 (4), pp. 513-520.

. (1989), "Marxismo de 'elección racional': algunas cuestiones de metodo y contenido", in J. Roemer (org.), El marxismo: uma perspectiva analítica, México, Fondo de Cultura Económica, pp. 219-230.

STUART MILL, John. (1886), System of logic ratiocinative and inductive being a connected view of the principles of evidence and the methods of scientific investigation. Londres, People's Edition (versão facsimile, capítulos I a XI, pp. 185-305).

TARRIT, Fabien. (2006), "A brief history, scope, and peculiarities of 'Analytical Marxism". Review of Radical Political Economics, 38: 595-618.

TSEBELIS, George. (1998), Jogos ocultos. São Paulo, Edusp.

WEBER, Max. ([1922] 1984), Economia y sociedad. México, Fondo de Cultura Económica. . (2004), "Critical studies in the logic of the cultural sciences: a critique of Eduard
Meyer's methodological view", in

The methodology of the social science. India, ADB

Publishers, 113-188 [translated and edited by Edward A. Shils and Henry A. Finch].

WRIGHT, Eric O. (1985), Classes. Londres, New Left Books.

WRIGHT, E. O.; LEVINE, A. \& SOBER, E. (1993), Reconstruindo o marxismo: ensaio sobre a explicação e a teoria da história. Petrópolis, Vozes. 


\section{MARXISMO E CIÊNCIA SOCIAL: UM BALANÇO CRÍTICO DO MARXISMO ANALÍTICO}

\section{Renato Perissinotto}

Palavras-chave: Marxismo analítico; Explicação funcional; Individualismo metodológico; Ciência social.

Este artigo discute as proposições críticas feitas pelos marxistas analíticos ao marxismo tradicional. Apresenta-se, num primeiro momento, o conteúdo dessas críticas, notadamente no que diz respeito à explicação funcional; num segundo momento, avalia-se em que medida é possível defender esse tipo de explicação; em seguida, discutem-se as propostas metodológicas feitas pelos marxistas analíticos, suas vantagens e limites; por fim, apresenta-se o que, a nosso ver, deve ser levado em consideração dessas críticas para que o marxismo se fortaleça como ciência social.

\section{MARXISM AND THE SOCIAL SCIENCE: A CRITICAL APPRAISAL OF ANALYTICAL MARXISM}

Renato Perissinotto

Keywords: Analytical Marxism; Functional explanation; Methodological individualism; Social science.

This article discusses the criticism made by analytical Marxists to theoretical and methodological statements of traditional Marxism. At first, the article presents the content of this criticism, especially those on functional explanation; afterwards, it evaluates in what extent is it possible to elaborate a defense of that kind of explanation; thirdly, it discusses the methodological proposal of the analytical Marxism and its limits and advantages; finally, we make some considerations on what must be taken into account in this criticism to strengthen Marxism as a social science.

\section{MARXISME ET SCIENCE SOCIALE: UN BILAN CRITIQUE DU MARXISME ANALYTIQUE}

\section{Renato Perissinotto}

Mots-clés: Marxisme analytique; Explication fonctionnelle; Individualisme méthodologique; Science sociale.

Cet article discute les propositions critiques faites par les marxistes analytiques au marxisme traditionnel. Dans un premier temps, nous présentons le contenu de ces critiques, notamment par rapport à l'explication fonctionnelle; puis, dans un second temps, l'article évalue dans quelle mesure il est possible de défendre ce genre d'explication. Nous discutons, ensuite, les propositions méthodologiques faites par les marxistes analytiques, leurs avantages et leurs limites. En conclusion, nous présentons ce qui, de ces critiques, doit être, d'après nous, considéré pour que le marxisme se renforce en tant que science sociale. 